\title{
Использование ускоренных методов оценки показателей надежности изделий ЭКБ отечественного производства - один из путей повышения их коммерческой привлекательности
}

\author{
А. Гербин, к. Ф.-м. н. ${ }^{1}$
}

УДК 621.37| ВАК 05.11 .01

\begin{abstract}
В статье проанализирован технический уровень отечественных разработок ЭКБ. С точки зрения автора, одним из инструментов повышения коммерческой привлекательности изделий ЭКБ ОП на мировом рынке может стать стандарт организации "Электронная компонентная база. Типовая методика ускоренных испытаний на надежнность", разработанная сектором исследований надежности управления испытаний ЭКБ ФГУП "МНИИРИП». Цель документа регламентация порядка и правил проведения ускоренных испытаний на надежность изделий ЭКБ на этапе их разработки и производства.
\end{abstract}

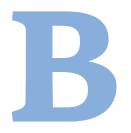

ходе анализа действующих стандартов, регламентирующих требования к показателям надежности изделий ЭКБ отечественного производства на этапе их разработки и производства, установлено, что основной причиной их низкой коммерческой привлекательности является применение морально устаревших действующих стандартов, регламентирующих требования по надежности и методы их контроля, вследствие чего разработчики ЭКБ не могут оценить фактические значения показателей надежности (ПН) изделий ЭКБ на этапе их разработки.

Проведенная Внешэкономбанком проверка результативности мероприятий федеральной целевой программы «Развитие электронной и радиоэлектронной промышленности» показала:

- технический уровень отечественных разработок ЭКБ - выше среднего;

- уровень их коммерческой привлекательности на мировом рынке продаж - низкий

Вероятно, еще одной причиной низкой коммерческой привлекательности новых разработок отечественных ЭКБ ОП является отсутствие объективных методик ускоренной оценки ПН изделий ЭКБ ОП на этапе их разработки и производства [1]

Требования к показателям надежности в Т3 (ТУ) достаточно высокие. Так, гамма-процентная наработка до отказа (Т $\left.{ }_{\gamma}\right)$ ЭКБ ОП достигла значений 100-150 тыс. ч

ФГУП «МНИИРИП», ведущий научный сотрудник сектора исследований надежности и более, а гамма-процентный срок сохраняемости $\left(T_{c \gamma}\right)-20-25$ лет

Методы подтверждения заданных в Т3 (ТУ) и регламентируемых ГОСТ РВ 20.57.414 значений ПН не соответствуют требованиям времени ни по длительности испытаний, ни по экономическим затратам, ни по времени реализации предложений по устранению выявленных конструкторско-технологических причин отказов электронных компонентов в процессе их эксплуатации в РЭА.

В 2015 году международный симпозиум по надежности ЭКБ отметил, что изделия ЭКБ России являются самыми ненадежными и малопривлекательными на мировом рынке продаж. Причиной низкой коммерческой привлекательности ЭКБ России является недостаточная достоверность определения фактических значений ПН изделий ЭКБ на стадии их разработки и производства [1]. Проблема обусловлена противоречием, возникшим между стандартами, регламентирующими требования к ПН ЭКБ (ГОСТ РВ 20.39.413), и методами их контроля (ГОСТ РВ 20.57.414) в условиях новых экономических взаимоотношений между заказчиками и разработчиками ЭКБ ОП.

Рассмотрим основные причины возникновения разногласий.

Указанные выше стандарты разрабатывались двадцать лет назад и предназначались для обслуживания командной экономики и в них не предусматривалось практическое применение ускоренной оценки Пн изделий ЭКБ на стадии их разработки и производства, 
также как и сокращение сроков проведения ОКР и их стоимости, повышение достоверности оценки фактических показателей надежности ЭКБ на этапе их разработки и производства, внедрение маркетинга разработчиками ЭКБ среди потребителей ЭКБ с целью завоевания рынка сбыта электронных компонентов. Потребитель был один - предприятия ВПК России с пятилетними планами их развития.

По каким основным положениям ГОСТ РВ 20.39.413 и ГОСТ РВ 20.57.414 не соответствуют требованиям мирового рынка продаж изделий ЭКБ?

Прежде всего, в стандартах заложены принципы оценки ПН изделий ЭКБ на этапе их серийного производства, а не на этапе их разработки, на котором закладывается основа их качества и надежности.

Согласно ГОСТ РВ 20.39.413, требования к надежности изделий ЭКБ задают путем нормирования показателей безотказности и сохраняемости.

При установлении требований в Т3 (ТУ) регламентируют:

- состав ПН и их нормы;

- типовой режим эксплуатации и условия хранения, применительно к которым устанавливают значения показателей надежности;

- критерии отказа изделий при функционировании и хранении;

- порядок и метод оценки соответствия изделий ЭКБ требованиям ТЗ.

Требования к ПН изделий ЭКБ соответствуют многолетнему опыту их серийного производства и испытаний в условиях командной экономики развития радиоэлектроники. Стандарт рекомендует устанавливать Пн, как правило, для типового режима эксплуатации. На практике проблема возникает как раз в определении типового режима эксплуатации изделий ЭКБ на стадии их разработки. По существу, в Т3 на ОКР указывается в лучшем случае два режима: номинальный (при повышенной температуре) и облегченный (при нормальной температуре) с целью увеличения значения $\mathrm{T}_{\gamma}$ для демонстрации достижений в развитии ЭКБ. На стадии разработки изделий ЭКБ расчетно-экспериментальными методами определяют зависимость показателя безотказности от уровня определяющего фактора окружающей среды и уровня электрической нагрузки. Результаты испытаний приводят в ТУ в виде справочных значений.

Вместе с тем требования к погрешности определения фактических значений ПН образцов изделий на стадии их разработки отсутствуют. Двухгодичный опыт проведения технических экспертиз методик испытаний на надежность, разрабатываемых в рамках ОКР, свидетельствует, что величины погрешностей определения фактических значений ПН опытных образцов изделий ЭКБ составляет 40-60\%. В большей части методик величина этой погрешности вообще не оценивается, что лишает потребителя ЭКБ уверенности в достоверности значений ПН, указанных в рекламных листах или ТУ.

Согласно ГОСТ РВ 20.39.413, оценку соответствия изделий ЭКБ требованиям надежности на стадиях разработки и производства осуществляют в соответствии с ГОСТ РВ 20.57.414.

Согласно ГОСТ РВ 20.57.414, испытания на безотказность включают в себя кратковременные (КИБ) и длительные (ДИБ) испытания. ДИБ проводят с целью подтверждения требований к $T_{\gamma}$ непосредственно по результатам испытаний или путем обобщения ранее проведенных результатов испытаний. Продолжительность испытаний на стадии разработки устанавливают в Т3, при этом продолжительность ДИБ должна быть не менее указанной для квалификационных испытаний, если иное не оговорено в Т3. По этим причинам оба направления не вызывают у потребителя привлекательности и уверенности в достоверности приведенных значений Пн.

На этапе ОКР объем выборки устанавливают исходя из характера производства (массовое, крупносерийное, мелкосерийное) и сложности испытательного и измерительного оборудования. При формировании Т3 на ОКР неизвестно, каким будет характер производства опытных образцов, но используют, как правило, табл. 4 стандарта, в которой объемы выборок составляют 3-6 приборов, как при мелкосерийном производстве.

Ускоренные испытания на надежность (п. 4.7) проводят по методам, установленным в ТУ на изделия или в других НТД, согласованных с Пз и НИО заказчика.

Вместе с этим и заказчик, и потребитель понимают, что на этапе разработки изделий НТД методики ускоренных испытаний на надежность (УИН) конкретных типов ЭКБ, согласованные с заказчиком, отсутствуют, так как разрабатываются новые изделия, у которых еще неизвестны параметры критериев годности и их нормы, да и типовых методик УИН тоже нет. Для того чтобы обойти этот пункт требований ГОСТ РВ 20.57.414 в Т3 на ОКР ввели требование: "Допускается испытания на безотказность проводить по методике ускоренных испытаний, согласованной с НИО, определяемой заказчиком ОКР», то есть департаментом радиоэлектронной промышленности Минпромторга России. Таким образом, на этапе ОКР необходимо разработать методику УИН, согласовывать ее с организацией, определяемой заказчиком, и провести ее метрологическую экспертизу. В этом случае важным для разработчика ЭКБ является не достоверность оценки ПН, а срок окончания ОКР, в силу того, что потребитель изделия ЭКБ один и обязан получить опытные изделия в сроки, указанные в согласованном графике их поставок. На этапе ОКР думать о коммерческой привлекательности продукции главному 
конструктору - нереальная задача. Да и процесс согласования методики УИн с организацией заказчика требует существенной переработки и уточнения. Место подразделения надежности организации заказчика в этом процессе по существу не определено (этап формирования Т3 на ОКР или этапы его выполнения в части оценки погрешностей определения фактических значений Пн изделий ЭКБ на стадии их разработки и др.).

Кратковременные испытания на безотказность (КИБ), регламентированные ГОСТ РВ 20.57.414, являются в этом случае "палочкой-выручалочкой». Согласно п. 4.9, КИБ проводят с целью контроля стабильности технологического процесса изготовления изделий. Но как можно осуществлять контроль стабильности технологического процесса изготовления ЭКБ, если параметры критерия стабильности их технологического процесса разработки и изготовления опытной партии ЭКБ (ПКС) и их нормы не определены и в Т3 не регламентированы. Возникает вопрос о целесообразности проведения КИБ не только на этапе разработки изделий, но и на этапе их производства (периодические испытания), так как значения параметров-критериев годности (ПКГ) при испытаниях на надежность и их нормы должны быть, как правило, равны нормам при приемке и поставке с учетом допустимых изменений в течение $T_{\gamma}\left(t_{\lambda}\right)$ и $\mathrm{T}_{c \gamma}$ (см. п. 4.14). Такая неопределенная формулировка приводит к тому, что каждый ПКГ по безотказности и сохраняемости имеет свою норму, которая и будет определять достоверность полученных фактических Пн.

Во-первых, ПкГ одни и те же, что при оценке безотказности кратковременной 500-1000 тыс. ч и длительной 100-150 тыс. ч и хранении. Например, коэффициент затухания оптического кабеля (OK) при $\mathrm{T}_{\gamma}$ должен быть таким же, как и при $\mathrm{T}_{c \text {. }}$. Следовательно, эксплуатация его после длительного хранения недопустима, хотя испытания на сохраняемость ОК выдержал успешно. Такая же ситуация по большинству изделий ЭКБ сложилась между КИБ и дИБ

Согласно ГОСТ РВ 20.57.414, продолжительность КИБ устанавливают в составе периодических и квалификационных испытаний по группе С в зависимости от величины $\mathrm{T}_{\gamma}\left(t_{\lambda}\right)$, но не более 5000 ч (см. п. 5.1.3). В Т3 на ОКР гамма-процентная наработка до отказа указывается 100-150 тыс. 4 при $ү=0$,97. Контроль заданных в Т3 ПН подтверждается путем проведения КИБ в предельно допустимом электрическом режиме эксплуатации, установленном в Т3 и при повышенной температуре среды или корпуса изделия, максимально допустимой для этого режима (см. п. 5.1.8). По существу, такое требование запрещает использование УИН опытных изделий ЭКБ на этапах их разработки, а это по существу красный свет для поиска путей разработки УИН ЭКБ и их применения в процессе их серийного производства (включения в ТУ).
Продолжительность испытаний ЭКБ на стадии их разработки устанавливают в Т3, при этом продолжительность испытаний должна быть не менее указанной для квалификационных испытаний в стандартах на группы изделий (см. п. 5.1.3 последний абзац). Требования пп. 5.1.3 и 5.1.8 противоречат друг другу и дают возможность разработчикам ЭКБ и их заказчикам на этапе ОКР использовать КИБ, что противоречит требованиям п. 5.1.3. Вместе с этим примечание к п. 5.1.8 ГОСТ РВ 20.57.414 допускает применение эквивалентных режимов и (или) схем испытаний. В этом случае конкретные значения электрических режимов и условий испытаний указывают в ТУ на изделия, которые могут появиться только после окончания ОКР с литерой «О» или «А».

Следовательно, никаких ТУ (как юридического документа) на этом этапе разработки изделий ЭКБ не может быть в принципе, остается только вариант типовой методики УИН ЭКБ, согласованной с ДРЭП Минпромторга России.

Время испытаний при использовании метода УИН устанавливают с учетом применения коэффициента ускорения $\left(\mathrm{K}_{\text {уин }}\right)$, рассчитанного по методикам, приведенным в ТУ на изделия или в других НТД, согласованных с Пз и ниО заказчика.

Напрашивается единственный выход из создавшегося тупика:

- в новой редакции ГОСТ РВ 20.57.414 ввести самостоятельные разделы по оценке ПН ЭКБ на стадии их разработки и на стадии их производства, основное внимание при этом уделив использованию Уин в серийном производстве, так как это потребует пересмотра (уточнения) объемов выборок ЭКБ, режимов их испытаний, периодичности испытаний и оценки их ПН и замены КИБ на УИБ на этапе периодических испытаний.

На основании далеко не полного анализа положений ГОСТ РВ 20.57.414 в части безотказности можно сделать следующие выводы:

1. Для определения фактических значений $\mathrm{T}_{\gamma}\left(\mathrm{T}_{c \gamma}\right)$ опытных образцов ЭКБ остается практически единственный способ - проведение УИН, при которых электронные компоненты подвергают испытаниям в условиях более высоких нагрузок, чем при их нормальной эксплуатации, так как УИН изделий ЭКБ могут обеспечить существенное ускорение процесса их старения, а деградацию ПкГ такой же, как и при нормальных условиях эксплуатации [2] .

2. Длительность УИн определяется коэффициентом ускорения и заданной в Т3 на ОКР гаммапроцентной наработкой до отказа $\left(\mathrm{T}_{\gamma}\right)$ или $\left(\mathrm{T}_{c \gamma}\right)$

$$
t_{\text {уиб }}=\mathrm{T}_{\gamma}^{\mathrm{T} 3} / \mathrm{K}_{\text {уиб }}
$$


3. Модель коэффициента ускорения отказов выбирается на основе изучения механизмов отказов конструктивно-технологических аналогов испытываемых изделий ЭКБ, для большинства которых повышение температуры окружающей среды, форсирование током и напряжением являются ускоряющими факторами .

4. Кратковременные испытания изделий ЭКБ на безотказность на этапе их разработки не имеют технического обоснования, и проводить их нецелесообразно (на этапе ОКР отсутствует необходимая статистика стабильности технологического процесса, а также ПкС и их нормы).

5. ПкГ ускоренных испытаний на безотказность должны соответствовать нормам, установленным для данного вида испытаний. Речь в данном случае идет не о КИБ длительностью 500-2000 тыс. ч, а о значении $\mathrm{T}_{\gamma}$ длительностью 100-150 тыс. 4 и при достоверности измерений ПКГ не хуже 95\%.

С оценкой сохраняемости изделий ЭКБ на этапе их разработки дело обстоит значительно сложнее, чем с безотказностью. Это обусловлено, с одной стороны, несовершенством ГОСТ РВ 20.57.414 в части методов проведения ускоренных испытаний на сохраняемость (УИС) и, с другой стороны, повышением требований заказчика к гамма-процентному сроку сохраняемости $\mathrm{T}_{c \gamma}=(25-30)$ лет при $\gamma=0,9$ и выше для изделий ЭКБ, вмонтированных в РЭА и не удовлетворяющих ее по срокам сохраняемости.

Как правило, такие изделия ЭКБ имеют срок сохраняемости 8-15 лет, но по своему функциональному назначению удовлетворяют требованиям РЭА. В этом случае, как правило, руководствуются требованиями ГОСТ 2.124-2014 (оформление разрешения на применение). Согласно ГОСТ РВ 20.57.414, подтверждение требований к сохраняемости в процессе ОКР проводят:

- по данным сохраняемости аналогов;

- расчетно-экспериментальными методами;

- методами ускоренных испытаний (при наличии соответствующих НТД).

Способ подтверждения требований к сохраняемости устанавливают в Т3 (см. п. 6.1).

Все три метода, указанные в п. 6.1 ГОСТ РВ 20.57.414, методами по существу не являются. Перечислены только лишь направления поиска приемлемого способа оценки срока сохраняемости изделия.

При выполнении процедуры УИС изделий ЭКБ на этапе их разработки и начинается творчество разработчиков электронных компонентов и согласующих организаций (ПЗ, тематический отдел и сектор исследований надежности МнИИРИП, представитель потребителя). В сложившейся ситуации консенсуса в таком споре не найти. Выход один - наличие типовой методики уис изделий ЭКБ в процессе их разработки и производства и разработка на ее основе методики УИС конкретных изделий ЭКБ для конкретных условий их хранения и эксплуатации в РЭА.

Все рекомендуемые направления оценки $\mathrm{T}_{c \gamma}$ требуют конкретизации в части механизма старения, перечня ПКГ и их норм, определения факторов ускорения в зависимости от условий хранения изделий ЭКБ, коэффициента ускорения, длительности УИС и сохранения автомодельности при УИС. Все эти направления в ГОСТ РВ 20.57.414 не рассматриваются, а основное внимание уделено нормальным испытаниям на сохраняемость в условиях хранения ГОСТ В 9.003-80. Причины такого положения изложены выше.

В конце испытаний на сохраняемость в нормальных условиях проводят кратковременные испытания изделий ЭКБ на безотказность. При этом объем выборки не должен превышать половины объема выборки, испытываемой на сохраняемость в нормальных условиях. Согласно приложению А.1 стандарта, объемы выборок для испытаний на сохраняемость составляют (для примера):

- приборы СВЧ - 40 шт.;

- ЭОП-40 шт.;

- ВИС - 24-120 шт.;

- микросхемы - 40-160 шт. (в зависимости от степени интеграции);

- полупроводниковые и СВЧ-приборы - 200 шт.;

- резисторы-100-200 шт.;

- конденсаторы - 50-200 шт.

При внедрении УИС опытных изделий ЭКБ на этапе их разработки использовать рекомендуемые ГОСТ РВ 20.57.414 объемы выборок для нормальных условий испытаний будет слишком дорого для предприятий - разработчиков ЭКБ.

Для начала, можно ограничиться объемом выборки для УИС 20 шт. изделий при $\gamma=95 \%$ или 10 шт. при $\gamma=90 \%$, но при этом установить переодичность проведения УИС.

Испытания на сохраняемость считаются положительными, если при испытании выборки изделий не произошло ни одного отказа, а результаты КИБ признаны положительными (см. п. 6.9 ГОСТ РВ 20.57.414).

Из краткого анализа основных положений ГОСТ РВ 20.57.414 в части методов контроля гаммапроцентного срока сохраняемости $\mathrm{T}_{c \gamma}$ можно сделать следующие выводы:

- нормальные испытания опытных изделий ЭКБ на сохраняемость на этапе их разработки, по большому счету, являются нецелесообразными по их длительности, стоимости и медленному внедрению предложений по совершенствованию конструкции и технологии их изготовления; 
- ускоренные испытания на сохраняемость и безотказность опытных образцов ЭКБ целесообразно проводить на одной выборке с периодичностью один раз в год (если иное не будет оговорено в Т3).

Результаты проведенного анализа будут не полными без краткого рассмотрения основных положений ГОСТ В 9.003-80 «Единая система защиты от коррозии и старения. Военная техника. Общие требования к условиям хранения". При рассмотрении основных положений ГОСТ 9.003-80 необходимо обратить внимание на следующее:

1. ГОСТ В 9.003 распространяется на вооружение и военную технику и устанавливает общие требования к условиям, местам и организации хранения. Стандарт не распространяется на изделия ЭКБ. По мнению многих разработчиков, необходима разработка ГОСТ Р «Электронная компонентная база и ее составляющие части. Общие требования к условиям хранения»;

2. Необходимо уточнить условия хранения изделий ЭКБ и их составных частей исходя из модульной конструкции электронных компонентов и технологических требований к их хранению. Целесообразно ограничить условия хранения ЭКБ в отапливаемых хранилищах с регулируемыми параметрами атмосферы (влажность, температура) и в специализированных помещениях для хранения изделий ЭКБ и их составных частей;

3. Уточнитьтакжеусловия хранения (ГОСТ РВ 20.39.413): - электронных компонентов, вмонтированных в защищенную аппаратуру;

- электронных компонентов, находящихся в защищенном комплекте Зип

По нашему мнению, если ЭКБ хранится в упаковках изготовителя в вышеуказанных условиях хранения, то изделия должны удовлетворять требованиям РЭА. Нет аппаратуры без вмонтированноЙ в нее ЭКБ.

4. Уточнить требования к помещениям хранения электронных компонентов и их составных частей.

На основании результатов краткого анализа стандартов регламентирующих требований к ПН ЭКБ ОП, методов их контроля и условий хранения можно сделать следующие выводы:

- действующие стандарты ГОСТ РВ 20.39.413, ГОСТ РВ 20.57.414 и ГОСТ В 9.003 морально устарели и не соответствуют новым экономическим условиям хозяйствования, являются основной причиной низкой коммерческой привлекательНОСТИ ЭКБ ОП;

- единственным оптимальным решением проблемы является разработка типовой методики ускоренной оценки ПН изделий ЭКБ на стадии их разработки и производства. По существу, разработка методики УИН ЭКБ и ее внедрение в практику их производства - это требование технического прогресса в части развития ЭКБ ОП и увеличения коммерческого спроса на новые разработки ЭКБ на мировом рынке.

В целях реализации требований ДРЭП Минпромторга России о необходимости повышения коммерческой привлекательности изделий ЭКБ ОП сектором исследований надежности Управления испытаний ЭКБ и СИ МнИИРИП разработана первая редакция проекта стандарта организации "Электронная компонентная база. Типовая методика ускоренных испытаний на надежность», целью которого является регламентация порядка и правил проведения УИН изделий ЭКБ на этапе их разработки и производства. В основу расчета продолжительности УИН положено моделирование процессов старения ЭКБ. В качестве моделей старения изделий ЭКБ выбраны:

- модель Аррениуса для изделий герметичного исполнения;

- модель Хеллберга-Пека для изделий негерметичного исполнения;

- модель Коффина-Менсона для условий хранения изделий в неотапливаемом помещении или под навесом

Сокращение продолжительности УИН изделий ЭКБ на стадии их разработки достигается применением форсированных условий испытаний, вызванных воздействием климатических факторов и электрических режимов эксплуатации

Автомодельность процесса старения конкретных типов изделий ЭКБ обеспечивается проведением экспериментальных исследований их энергии активации. Порядок и правила проведения экспериментов по определению энергии активации достаточно подробно регламентированы в ГОСТ Р 57394-2017 (Приложение Г) [3].

\section{ЛИТЕРАТУРА}

1. Артюхова М.А., Полесский С. Н. Исследование надежности моделей интенсивности отказов полупроводниковых приборов // вшэ России. Труды международного симпозиума "Надежность и качество». Т. 1. 2015

2. Куликов И. В. Экспериментальное определение энергии активации процесса старения изделий по результатам форсированных испытаний. ЭТ. 1983. Вып. 6 (105).

3. ГОСТ Р 57394-2017. Микросхемы интегральные и приборы полупроводниковые. Методы ускоренных испытаний на безотказность. 

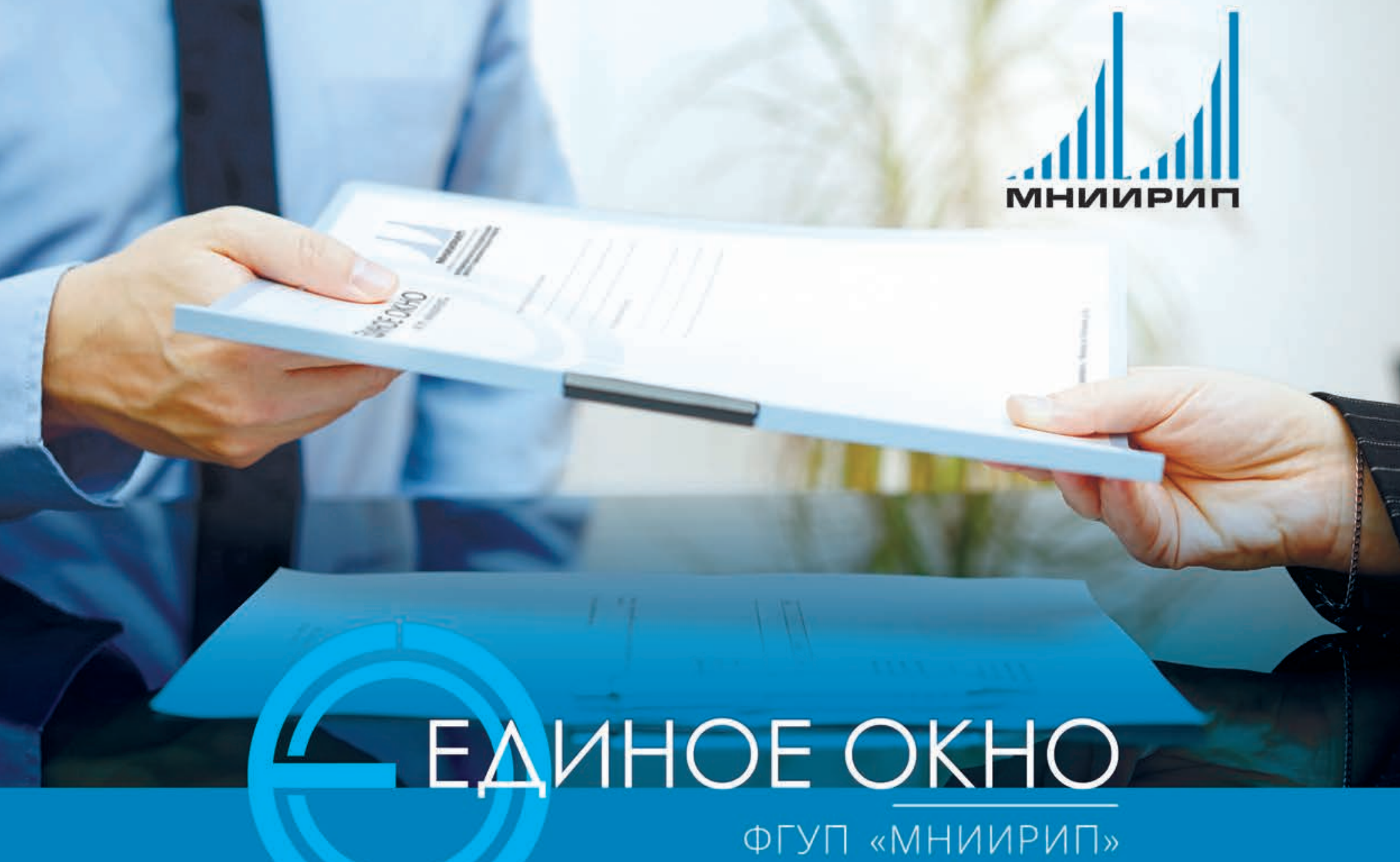

\section{МНОГОФУНКЦИОНАЛЬНЫЙ ЦЕНТР РАДИОЭЛЕКТРОНИКИ - ЕДИНОЕ ОТРАСЛЕВОЕ ИНФОРМАЦИОННОЕ ОКНО}

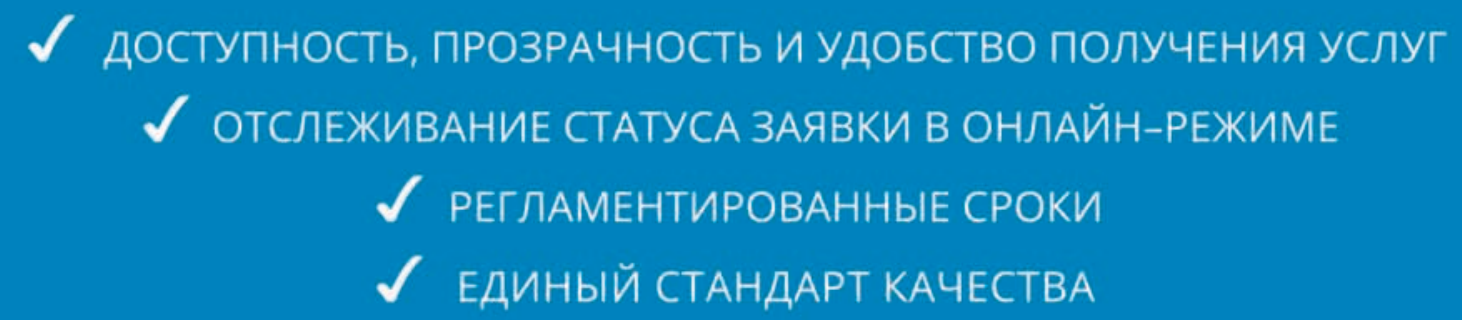

ФГУП «МНИИРИП»

Головная научно-исследовательская испытательная организация Минпромторга России в области ЭКБ www.mniirip.ru info@mniirip.ru

Московская область, г. Мытищи, ул. Колпакова, д. 2а 